any impediment to its complete and quick action on the nervous or absorbing surface with which it is brought into contact. It is certain, that in the case of acetate of morphia, where, perhaps, this preference has been more shown, and the propriety of which has been less called in question than in any other instance, there must be some fallacy in the circumstances supposed to prove its superiority over the muriate; for there can hardly fail to be as much muriatic acid in the stomach, in the greater number of cases, as would be sufficient to decompose the acetate - a consequence resulting from its acid being so far behind the muriatic in strength of affinity; so that, although the acetate be the salt taken, the action on the system is that of a muriate, and not of an acetate.

In fixing our choice on the salt deserving of preference, the reasons on which we should found our judgment should be of a description somewhat like the following:- Which is the most readily and easily prepared? which is most readily got in a state of purity, and sufficiently soluble? and which is least liable to change or decomposition? Taking these characters for guides, in the case of the morphia salts, the muriate ought decidedly to get the preference. In the case of the quinine salts, the sulphate should be preferred, for on account of its sparing solubility on crystallizing, the greater part of the impurities are left behind in the abundant mother liquid.

It has also occurred to us, that it might be advantageous to medical men to suggest, that in administering externally some of the alkaloids, such as aconitina and veratria, in the form of ointment, the activity of the remedy would be more effectually secured by dissolving them in a few drops of a weak acid, such as the acetic, before mixing them with the ointment. In this way their absorption is more effectually secured, and disappointment in the result less likely to happen. In the case of aconitina, we have in this way proved on our own persons its increased activity; and if we mistake not, there is a fact of a similar nature in Dr. Fleming's lately published essay on "Aconitum."

Duke-street, Edinburgh, March, 1846.

\section{CASE OF HYDATIDS OF THE UTERUS COINCIDENT WITH PREGNANCY.}

By George Yeates Hunter, Esq., Surgeon, Margate.

ON Monday, March 30th, about six o'clock P.M., I was called to Mrs. B-, aged 23, in labour with her second child, Mr. W. H. Thornton, my assistant, who was engaged to attend, being absent.

On examination per vaginam, I found the os uteri dilated, and the head presenting; but the presentation was by no means distinct, and was ascertained with some difficulty, because a soft pulpy mass (evidently not the placenta) intervened between the presenting part and my finger.

After a few pains the membranes ruptured, at which time I heard a very peculiar crackling noise, and on again examining my patient, the infant's head had passed below the pulpy mass, which was now beyond my reach. The labour progressed very favourably, and the child, which was small, was born in less than two hours after my arrival. Mr. Thornton had arrived just before the child was born.

After waiting some time, it became necessary to remove the placenta. When the hand was introduced for that purpose, the uterus was found distended by what afterwards proved to be hydatids, measuring about three pints. They were in clusters, like bunches of grapes, some of them being the size of hot-house grapes, but others, and by far the greater number, of the size only of the common blue cluster grape.

When the placenta was detached, we found it lobulated, and of an average size; the hydatids appeared to have been attached to a part of its margin, as well as to the uterus. I have preserved a great portion of these hydatids and the placenta, of which I mean to make a preparation, for presentation to the College of Surgeons, should they think it worthy of a place in their museum.

The patient is going on very well; no untoward symptoms have yet shown themselves.

I am well aware that hydatids in the uterus have sometimes been met with, but I never saw, nor heard of, a case in which they were found in the pregnant uterus. I have shown the hydatids in this case to my medical friends in this neighbourhood, who consider the case unique and interesting.

It should be remarked, that there were in the above woman's case, no unusual symptoms during the progress of her pregnancy. I shall endeavour to keep this patient in view, for the purpose of ascertaining whether or not other hydatids are formed, either during, or in the absence of pregnancy.

Cecil-square, Margate, April, 1846.
ON THE

CAUSES, PATHOLOGY, AND TREATMENT

\section{DEFORMITIES IN THE HUMAN BODY.}

\author{
(WITH CASES AND ENGRAVINGS.)
}

\section{Bx JOHN BISHOP, ESQ., F.R.S.,}

FELLOW OF THE ROXAL COLLEGE OF SURGEONS OF RNGLAND, SURGEON TO THE NORTHERN DISPENSARY, LATE SHNIOR SURGEON TO THE ISLINGTON DISPENSARY, ETC.

\section{No. IV.}

MECHANICAL CAUSES OF DISTORTION.

Effects of occupation.-Lateral deformities of the spine referrible to the necessity of the body obeying the laws of equilibrium, and movement of bodies in general. - D'Alembert's principle.Position of the centre of gravity determined; solution of the problem of the maximum base of support in a given position; effects of weight on the attitudes of the body; effects of the use of the common wooden-leg, and also of the improved wooden-leg.

Amonass the numerous occupations tending to distort the spine, may be mentioned those of watermen, waiters, harpplayers, porters, and the London milkmen, to which may be added unequal lengths of leg, wooden-legs, crutches, \&c. In almost all cases of lateral curvature resulting from mechanical causes, the altered form of the spine arises from the necessity that exists for the maintenance of equilibrium in all parts of the body under every change of posture, or application of extraneous force. All attempts to restore the figure by any other method than that of counteracting the disturbing foree that has given rise to the deformity, must therefore riecessarily fail. This being the principle on which the theory of the causes and treatment of such distortions is founded, we should endeavour to obtain a clear notion of the conditions requisite for the equilibrium of the body under different circumstances. The various attitudes which the several parts of the body are compelled to assume, in order to keep it in a state of equilibrium in different positions, are all referrible to the place of the centre of gravity, which must always be situated in a vertical line, passing within the base of support. If this fact, together with the effects of extraneous forces acting on the body, had been sufficiently studied by surgeons generally, the methods now adopted for the cure of distortions of the spine would never have been introduced.

When the body is acted on by any extraneous force or forces, the conditions necessary for a state of equilibrium are comprised in the following theorem.* In whatever manner several bodies forming a system change their motions, if we conceive that the motion which each body, were it quite free, would have in the succeeding instant is decomposed into two others, of which one is the motion which it really takes in consequence of the mutual actions of the whole system, the second must be such, that if each body were impelled by this force alone, (that is, by the force which would produce this second motion, all the bodies would remain in equilibrio. To find the distance of the head and feet from the centre of gravity of the human body in a horizontal position, it is merely necessary to balance the body placed upon a plane $a b$, on a triangular prism $d e$, as in fig. 1 ; then draw a line on

Frg. 1.

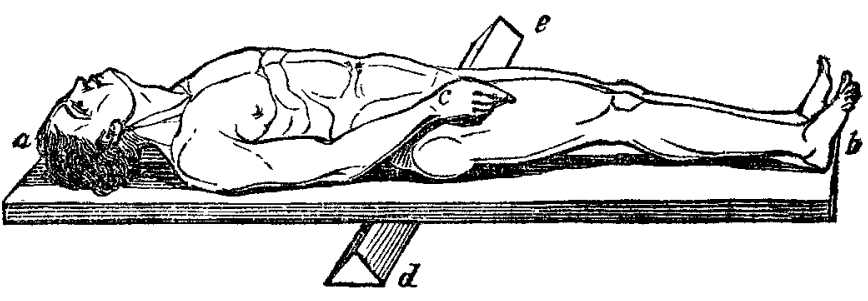

the plane close to the edge of the prism; again balance the body in another position, and draw a line as before, the vertical line passing through $c$, the intersection of these lines will pass through the centre of gravity. After the plan of Borelli, Weber balanced a plank across a horizontal edge, and stretched upon it the body of a living man; and he found, when the whole was in a state of equilibrium, (in which the method of double weighing was adopted,) by accurate measurements, the total length of the body-

* This is the celebrated principle of D'Alembert, by means of which all questions of motion are reduced to those of equilibrium. It supplies direct method of throwing dynamical problems into equations, and the difficulty is thus reduced to the solving of problems in pure nathematics. 